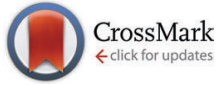

Cite this: Phys. Chem. Chem. Phys., $2015,17,25755$

Received 24th February 2015, Accepted 10th March 2015

DOI: $10.1039 / c 5 c p 01122 a$

www.rsc.org/pccp

\section{UV spectroscopy of cold ions as a probe of the protonation site $\dagger$}

\author{
Géraldine Féraud, $\$$ Natalia Esteves-López, Claude Dedonder-Lardeux and \\ Christophe Jouvet*
}

\begin{abstract}
The best determination of the most stable protonation site in aromatic molecules relies nowadays on the IR spectroscopy and $a b$ initio calculations. It appears that these methods are not necessarily unambiguous and cannot always be safely employed. We present in this paper an example showing that electronic spectroscopy of cold ions complemented with ab initio calculations gives clear results on the protonation site. In the example given on the aminophenol isomers (in ortho, meta and para positions), the protonation site is assigned from the electronic spectroscopy and in particular we show that for the meta isomer the proton is not on the amino group as observed for the other isomers. It shows also that the protonation site is not conserved in the electrospray evaporation-ionization process.
\end{abstract}

\section{A Introduction}

Protonated aromatic hydrocarbon molecules, $\mathrm{AH}^{+}$, constitute a fundamental class of organic molecules occurring as short-lived intermediates in various environments, from astrochemistry, jet engine gas exhaust, organic chemistry to biophysics. For example, $\mathrm{AH}^{+}$are widely accepted as intermediates in electrophilic aromatic substitution reactions ( $\sigma$ complexes), an important reaction mechanism of aromatic molecules, and thus the protonation site governs the stereochemistry.

In the past, NMR and IR spectroscopy were employed to characterize $\mathrm{AH}^{+}$ions in the condensed phase. ${ }^{1-3}$ In solution, intrinsic properties of $\mathrm{AH}^{+}$are difficult to characterize, due to the strong interaction with surrounding solvent molecules and counter ions. Gas-phase studies of $\mathrm{AH}^{+}$are required to elucidate the properties of the ions. Structural and energetic information has been obtained from mass spectrometry experiments, but the results are not unambiguous. In particular, these techniques provide indirect structural determination of the protonation site, since the information is basically obtained from systems heated either by collisions leading to dissociation or by collision with a

CNRS, Aix Marseille Université, PIIM, Physique des Interactions Ioniques et Moléculaires (UMR-7345), 13397 Marseille Cedex 20, France.

E-mail: Christophe.jouvet@univ-amu.fr

$\dagger$ Electronic supplementary information (ESI) available: Mass spectra of photon induced fragmentation for protonated aminophenol isomers; evaluation of the temperature of the ions in the cold ion trap; calculated ground state energies for the trans ortho-aminophenol $\mathrm{H}^{+}$and para-aminophenolH $\mathrm{H}^{+}$; comparison between gas phase photofragmentation spectra of protonated aminophenols and liquid phase absorption spectra of $m$-aminophenol at different pHs. See DOI: 10.1039/c5cp01122a \$ Present address: Departement f. Chemie und Biochemie, Universität Bern, 3012 Bern, Schweizer. proton acceptor/donor. In both cases, the collisional energies involved are larger than the energy for proton isomerization (in the order of $1 \mathrm{eV}$ ) and the proton is not necessarily well localized (mobile proton) when the reactive event occurs.

Recently spectroscopic techniques, mainly IR spectroscopy, have been extensively used to derive the structure of the ions. ${ }^{4-12}$ With the development of mass spectrometry experiments near the free electron laser facility ${ }^{13-15}$ the infrared spectra are obtained from multiphoton absorption leading to dissociation, which is not a linear process, thus there is no guarantee that all the vibrations can be observed. Additionally, the excitation energies being high and the experiments being performed at room temperature, vibrational bands are not very narrow and more than one tautomer can coexist in the ion trap. This makes the interpretation difficult, and as shown for example in the case of Ala-Ala ${ }^{16}$ the position of the proton may not be clearly defined (mobile proton).

The electronic spectroscopy of cold protonated ions has made considerable progress these past ten years with the development of cold ion traps ${ }^{17-21}$ and the question we would like to address in this paper is the following: can we identify the protonation site by analyzing the electronic spectra? To answer this question, we studied the different isomers of a simple protonated aromatic molecule, aminophenol i.e., o-aminophenolH ${ }^{+}$(or 2-aminophenolH ${ }^{+}$), $m$-aminophenolH ${ }^{+}$(or 3-aminophenolH $\mathrm{H}^{+}$), $p$-aminophenolH ${ }^{+}$ (or 4-aminophenol $\mathrm{H}^{+}$). Indeed, the experimental results presented here show that the electronic spectroscopy of cold ions, in combination with excited-state $a b$ initio calculations, is an alternative tool to get information on the protonation site.

Moreover, there is an active discussion on the relationship between the most stable ions in solution and the ions obtained in the gas phase after the electrospray process. ${ }^{22,23}$ For protonated aminophenol, the solvent stabilization of one conformer 
versus the others is quite large, so that the most stable tautomer is not the same in the gas phase and in the liquid phase (vide infra). This is then an ideal system to discuss this issue.

\section{B Methodology}

\section{Experimental}

The experimental setup has been presented previously ${ }^{19}$ and is just outlined here. The electronic spectra of the protonated aromatic ions were obtained via parent ion photo-fragment spectroscopy in a cryogenically-cooled Paul trap, the protonated ions being produced in an electrospray source. The ions are injected in the trap and thermalized at a temperature of around $40 \mathrm{~K}$ through collisions with the cold Helium buffer gas. The ions are kept in the trap for several tens of ms before the photo-dissociation laser is triggered. After laser excitation, the ions are extracted to a TOF mass spectrometer and the fragment(s) ion signal is recorded as the laser wavelength is scanned. Photo-dissociation is achieved with an OPO laser light source from EKSPLA (NT342B). The absence of vibrational hot bands indicates that the temperature of the ions is less than $50 \mathrm{~K}$ (see the case of protonated acridine in Fig. S2 of the ESI $\dagger$ ).

\section{Calculations}

$A b$ initio calculations have been performed with the TURBOMOLE program package, ${ }^{24}$ making use of the resolution-of-the-identity (RI) approximation ${ }^{25}$ for the evaluation of the electron-repulsion integrals. The equilibrium geometry of the protonated species in their ground states $\left(\mathrm{S}_{0}\right)$ has been determined at the MP2 and DFT/B3LYP levels. Vertical excitation energies of the lowest excited singlet states have been determined at the RI-ADC(2) (second order Algebraic Diagrammatic Construction) ${ }^{26}$ level since TD-DFT is suffering from the bad representation of charge transfer states. Calculations were performed with the correlation-consistent polarized valence double-zeta (cc-pVDZ) basis set, and some values were checked with the triple-zeta cc-pVTZ basis set. To get an idea on the relative stability of the proton site in the liquid phase, we used the Conductor-like Screening Model (COSMO) ${ }^{27}$ as implemented in Turbomole.

\section{Results}

The experimental photofragmentation spectra obtained for the three isomers are presented in Fig. 1. These spectra are recorded by monitoring the sum of the fragment ion signals as a function of the laser wavelength. For $p$-aminophenolH $\mathrm{H}^{+}$, the two main fragmentation channels are the loss of $\mathrm{NH}_{3}$ and loss of hydrogen atoms, the loss of $\mathrm{H}_{2} \mathrm{O}$ being a minor channel. The $\mathrm{H}$ loss channel is not seen in CID experiments, it is specific of the electronic excitation and the $\mathrm{NH}_{3} / \mathrm{H}$ ratio changes with the photon energy, which has been explained in the framework of the $\pi \pi^{*}-\pi \sigma^{*}$ interaction model $^{28}$ in a previous paper. ${ }^{29}$ This channel is not observed in the photo-dissociation of

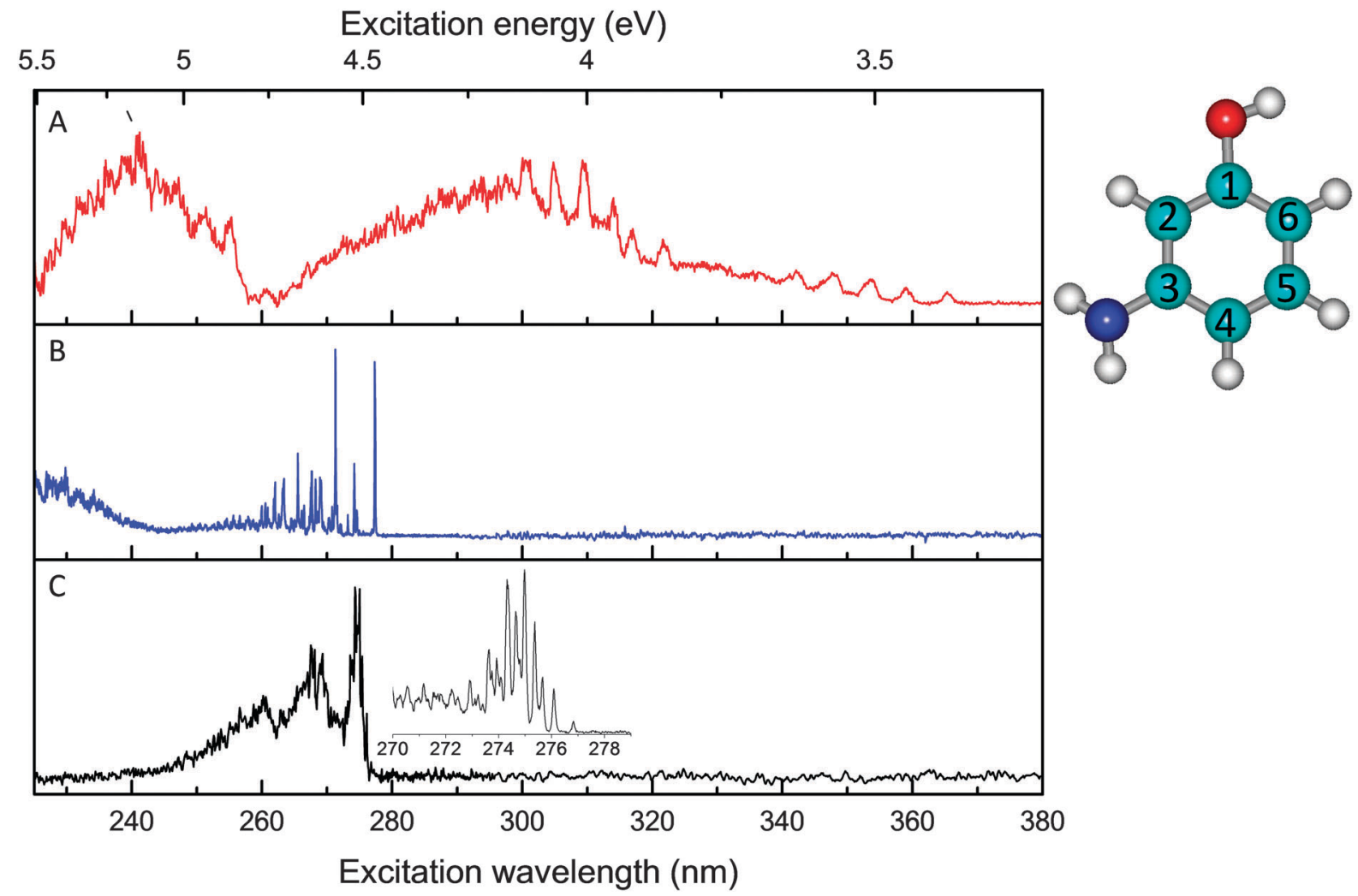

Fig. 1 Photofragmentation spectra of protonated aminophenol. (A) meta-AminophenolH $\mathrm{H}^{+}$; (B) para-aminophenolH ${ }^{+}$; (C) ortho-aminophenolH ${ }^{+}$. For the ortho-aminophenol $\mathrm{H}^{+}$photofragmentation spectrum, the low frequency vibrations near the $0-0$ transition are presented in the inset. In the right corner the numbering of the atoms is presented in the case of neutral trans meta-aminophenol. 
$m$ - and $o$-aminophenolH ${ }^{+}$. For meta- and ortho-aminophenolH ${ }^{+}$, the fragments are $m / z 92$ and 93, corresponding to the loss of $\mathrm{NH}_{3}$ and $\mathrm{H}_{2} \mathrm{O}$, which are the same as the CID fragments. It can be noticed that $o$-aminophenolH $\mathrm{H}^{+}$is the only isomer for which the $\mathrm{H}_{2} \mathrm{O}$ loss is the most important fragmentation channel (see mass spectra in Fig. S1 of ESI $\dagger$ ), the ratio between the two fragments being independent of the photon energy. For meta-aminophenolH ${ }^{+}$, an increase of secondary fragmentation $(\mathrm{m} / \mathrm{z} 65)$ is observed above $5 \mathrm{eV}$.

It should be reminded that the photo fragmentation spectra are not absorption spectra since the fragmentation yield depends on the excitation energy. The excitation energy must be above the fragmentation threshold, unless two-photon absorption occurs. In our case the fragmentation threshold ${ }^{15}$ is lower $(3 \mathrm{eV})$ than the first observed band $(3.5 \mathrm{eV})$ and thus the variation of the fragmentation with the excess energy will be reflected in the fragmentation time more than in the yield, but in the present case the fragmentation is detected a long time (tens of ms) after the excitation.

\section{para-AminophenolH ${ }^{+}$}

The $p$-aminophenolH ${ }^{+}$photofragmentation spectrum (Fig. 1B) has already been reported previously. ${ }^{29}$ It presents a very intense $0-0$ transition and narrow vibronic bands. This electronic spectrum is quite similar to the spectrum of cold neutral $p$-aminophenol. ${ }^{30}$ This similarity and the comparison with ground and excited states $a b$ initio calculations clearly indicate that the proton is localized on the amino group.

\section{ortho-AminophenolH ${ }^{+}$}

The photofragmentation spectrum of $o$-aminophenolH ${ }^{+}$(Fig. 1C) is as a whole similar to that of $p$-aminophenolH ${ }^{+}$, but also presents vibrational progressions on a low frequency mode $\left(96 \pm 1 \mathrm{~cm}^{-1}\right)$ as in its neutral homologue ${ }^{31}$ or in fluorophenol. ${ }^{32}$ This is due to the steric hindrance between the amino group (or the $\mathrm{F}$ atom) and the hydroxyl group, which imposes weak out of plane deformation. The band origin of $o$-aminophenolH ${ }^{+}$at $276.82 \mathrm{~nm}(4.48 \mathrm{eV})$ is very close to that of the $p$-aminophenolH ${ }^{+}$isomer $(277.36 \mathrm{~nm})$.

\section{meta-AminophenolH ${ }^{+}$}

The photofragmentation spectrum of $m$-aminophenolH ${ }^{+}$(Fig. 1A) is very much red-shifted as compared to the $o$ - and $p$-aminophenolH ${ }^{+}$ spectra. Indeed, the origin of its first electronic excited state is located at $365.4 \mathrm{~nm}(3.39 \mathrm{eV})$ i.e. more than $1 \mathrm{eV}$ lower in energy than the band origin of the other isomers. Two other band systems are observed starting at $321.8 \mathrm{~nm}(3.85 \mathrm{eV})$ and $255.3 \mathrm{~nm}(4.86 \mathrm{eV})$. Moreover, all the vibrational bands are very broad (FWHM $\approx$ $200 \mathrm{~cm}^{-1}$ instead of $15 \mathrm{~cm}^{-1}$ for the $p$-aminophenolH ${ }^{+}$bands) and separated by about $500 \mathrm{~cm}^{-1}$. At this point it is not possible to state whether these band systems belong to the different electronic states of the same tautomer of $m$-aminophenolH ${ }^{+}$or to different tautomers. It is quite clear that the electronic spectrum is drastically different from those of the other isomers and thus the proton is not located on the amino group: the spectrum of the tautomer protonated on the amino group $\left(\mathrm{NH}_{3}^{+}\right)$should exhibit a strong transition around $277 \mathrm{~nm}$, which is not observed, indicating that this tautomer is not present (or in very low abundance) in the ion trap at a low temperature $(50 \mathrm{~K})$.
Further assignment of the tautomers possibly observed requires $a b$ initio calculations.

\section{Calculations}

para and ortho-aminophenolH ${ }^{+}$. The assignment of the different tautomers that can be involved in the photofragmentation spectra relies on two calculated values, the ground state energy and the $\mathrm{S}_{1} \leftarrow \mathrm{S}_{0}$ transition energy. For protonated $o$ - and $p$-aminophenol, the assignment is very simple and without ambiguity. The ground state calculations (with both DFT and MP2 methods) predict that the protonation site on the amino group is more stable by more than $0.2 \mathrm{eV}^{15}$ for $p$-aminophenolH $\mathrm{H}^{+}$ and more than $0.3 \mathrm{eV}$ for $o$-aminophenol $\mathrm{H}^{+}$as compared to other positions of the proton on carbon atoms of the aromatic ring (see ESI, $\dagger$ ). For $o$-aminophenolH $\mathrm{H}^{+}$, there could be two orientations (cis and trans) of the hydroxyl group with respect to the ammonium group, however a ground state optimization starting from the cis geometry leads without a barrier to the trans geometry. In addition, the electronic transition of the trans o-aminopheno $\mathrm{H}^{+}$tautomer protonated on the amino group (trans ortho $\mathrm{NH}_{3}{ }^{+}$isomers: isomers protonated on the amino group are denoted $\mathrm{NH}_{3}{ }^{+}$in the next paragraphs) is calculated within $0.10 \mathrm{eV}$ of the experimental band origin (i.e. less than 5\% error), as shown in Table 2.

meta-AminophenolH ${ }^{+}$. The situation is more complex for $m$-aminophenolH ${ }^{+}$: for each proton location, there are cis and trans conformations depending on the orientation of the $\mathrm{OH}$ group versus the amino group in the meta position.

The ground state energies of different $m$-aminophenolH ${ }^{+}$ isomers have been calculated at two levels of theory (MP2 and DFT) and are presented in Table 1, where the isomers protonated on the amino group are labeled cis and trans $\mathrm{NH}_{3}{ }^{+}$and the tautomers protonated on carbon atoms (see Fig. 1 for atom numbering) are labeled cis or trans $\mathrm{CnH}^{+}$.

As can be seen in Table 1, there is a strong discrepancy between MP2 and DFT methods mostly for the $\mathrm{NH}_{3}{ }^{+}$tautomer. At the MP2/cc-pVDZ level of calculation, the $\mathrm{C}_{6} \mathrm{H}^{+}$and $\mathrm{NH}_{3}{ }^{+}$ tautomers (both cis and trans) have their ground state energy within less than $0.07 \mathrm{eV}$, which can be considered as within the calculation error. But at the DFT/B3LYP level, the $\mathrm{C}_{6} \mathrm{H}^{+}$

Table 1 Ground state energies of the $m$-aminophenolH ${ }^{+}$isomers (all the values are in eV): the energies are referenced to the energy of the cis $\mathrm{C}_{6} \mathrm{H}^{+}$ tautomer (i.e. the proton is on the $\mathrm{C} 6$ carbon atom of the aromatic ring as numbered in Fig. 1)

\begin{tabular}{llll}
\hline $\begin{array}{lll}\text { m-AminophenolH } \\
\text { isomers }\end{array}$ & $\begin{array}{l}\text { Relative energy } \\
\text { DFT/B3LYP/ } \\
\text { cc-pVDZ }\end{array}$ & $\begin{array}{l}\text { Relative } \\
\text { energy } \\
\text { MP2/cc-pVDZ }\end{array}$ & $\begin{array}{l}\text { Relative energy } \\
\text { DFT/B3LYP+ } \\
\text { COSMO/cc-pVDZ }\end{array}$ \\
\hline cis $\mathrm{C} \mathrm{H}^{+}$ & 0.00 & 0.00 & 0.00 \\
trans $\mathrm{C}^{+} \mathrm{H}^{+}$ & 0.06 & 0.05 & 0.03 \\
cis $\mathrm{C}^{+} \mathrm{H}^{+}$ & 0.09 & 0.10 & 0.11 \\
trans $\mathrm{C}_{4} \mathrm{H}^{+}$ & 0.10 & 0.12 & 0.09 \\
trans $\mathrm{C}^{+} \mathrm{H}^{+}$ & 0.19 & 0.25 & 0.18 \\
cis $\mathrm{C}^{+} \mathrm{H}^{+}$ & 0.33 & 0.41 & 0.27 \\
trans $\mathrm{NH}_{3}^{+}$ & 0.34 & -0.01 & -0.21 \\
cis $\mathrm{NH}_{3}^{+}$ & 0.42 & 0.07 & -0.19 \\
trans $\mathrm{C}^{+} \mathrm{H}^{+}$ & 1.45 & 1.47 & 1.47 \\
cis $\mathrm{C} 5 \mathrm{H}^{+}$ & 1.50 & 1.52 & 1.51
\end{tabular}


Table 2 Transition energies calculated for the first electronic states of the $0^{-}$, $m$ - and $p$-aminophenol protonated isomers. For $O$ - and $p$-aminophenolH $\mathrm{H}^{+}$, only the most stable $\mathrm{NH}_{3}{ }^{+}$isomers are tabulated while for $m$-aminophenolH $\mathrm{H}^{+}$ several tautomers are included. Calculations are performed at the ADC(2)/ cc-pVDZ level. All energies are in eV

\begin{tabular}{llll}
\hline Isomer & $\begin{array}{l}\text { Vertical } \\
\mathrm{S}_{1} \leftarrow \mathrm{S}_{0}\end{array}$ & $\begin{array}{l}\text { Adiabatic } \mathrm{S}_{1} \leftarrow \mathrm{S}_{0} / \\
\text { corrected } \Delta \mathrm{ZEE}^{a}\end{array}$ & Experiment \\
\hline cis meta $\mathrm{NH}_{3}{ }^{+}$ & 4.90 & $\mathrm{NH}_{3}$ loss & \\
trans meta $\mathrm{NH}_{3}{ }^{+}$ & 4.89 & 4.53 & \\
cis meta $\mathrm{C}^{+} \mathrm{H}^{+}$ & 4.51 & 3.59 & 3.85 \\
trans meta $\mathrm{C}^{+} \mathrm{H}^{+}$ & 4.41 & 3.54 & \\
cis meta $\mathrm{C}^{+} \mathrm{H}^{+}$ & 3.97 & Conical intersection & \\
trans meta $\mathrm{C}^{b} \mathrm{H}^{+}$ & 4.06 & 3.34 & 3.39 \\
trans ortho $\mathrm{NH}_{3}{ }^{+}$ & 5.00 & $4.70 / 4.57$ & 4.48 \\
para $\mathrm{NH}_{3}{ }^{+}$ & 4.92 & $4.74 / 4.57$ & 4.47 \\
& $4.81^{c}$ & $4.62 / 4.45^{c}$ &
\end{tabular}

${ }^{a}$ Transition corrected for the difference in zero point energy between ground and excited states. ${ }^{b}$ The ground and excited states become too close to get a convergence in the calculations, which indicates a conical intersection. ${ }^{c}$ MP2_ADC(2)/aug-cc-pVDZ.

tautomer is more stable than the $\mathrm{NH}_{3}{ }^{+}$tautomer by $0.3 / 0.4 \mathrm{eV}$, which is far from the usual uncertainty in such calculations. Calculations with an extended basis set (cc-pVTZ) give similar results. So for the $\mathrm{NH}_{3}{ }^{+}$tautomer of $m$-aminophenolH ${ }^{+}$, ground state calculations seem to be in trouble.

For the other ${\mathrm{C} n \mathrm{H}^{+}}^{(}(n=2,4,5)$ tautomers, DFT and MP2 methods agree quite well. The cis and trans $\mathrm{C} 4 \mathrm{H}^{+}$and $\mathrm{C}_{2} \mathrm{H}^{+}$may be considered as potentially involved in the $m$-aminophenolH ${ }^{+}$ photofragmentation spectrum since their ground state energies are not very high as compared to that of $\mathrm{C}^{\circ} \mathrm{H}^{+}$(see Table 1).

Calculations at the DFT/B3LYP+COSMO level were performed to investigate the relationship between the protonation sites in solution (before the electrospray evaporation) and in the gas phase. These calculations indicate that protonation on the amino site is clearly more stable than on the C6 site in the liquid phase (MP2+COSMO calculations give the same results).

\section{Excited states}

From the excited state calculations and comparison with the paraand ortho- isomers in which the proton is located on the amino group, it is clear that the cis and trans $\mathrm{NH}_{3}{ }^{+}$meta tautomers should be characterized by sharp transitions in the $277 \mathrm{~nm}$ region, which are not observed. The vertical transitions for cis and trans $\mathrm{C}_{6} \mathrm{H}^{+}$ meta-aminophenolH ${ }^{+}$tautomers are calculated to be $4.51 \mathrm{eV}$ and $4.41 \mathrm{eV}$, respectively, i.e. red shifted by $0.4 \mathrm{eV}$ compared to the transition of the $\mathrm{NH}_{3}{ }^{+}$meta tautomers. Upon excited state optimization, there is a strong change of geometry for both species leading to a stabilization energy of around $1 \mathrm{eV}$. The transition energies have also been calculated for the cis and trans $\mathrm{C}_{4} \mathrm{H}^{+}$and $\mathrm{C}_{2} \mathrm{H}^{+}$meta tautomers, which have their ground state energies less than $0.4 \mathrm{eV}$ above the ground state energy of the $\mathrm{C} \mathrm{H}^{+}$tautomer.

\section{Discussion}

\section{Assignment}

The electronic spectra of the three isomers are very different, considering the positions and widths of the bands. The most stable isomers of $o$ - and $p$-aminophenol $\mathrm{H}^{+}$are the ones with the proton on the amino substituent, and they show electronic transitions in the UV $(\sim 277 \mathrm{~nm})$ and their spectroscopy is similar to the anilinium one. ${ }^{29}$ In contrast, $m$-aminophenolH ${ }^{+}$ has a characteristic spectrum in the near UV (origin at $365.4 \mathrm{~nm}$ ) i.e., red-shifted as compared to the spectra of the other two isomers. These transitions to the red part of the spectrum are assigned to tautomers of $m$-aminophenolH ${ }^{+}$with the proton on a carbon atom of the cycle and not on the amino group. Moreover, the vibrational progressions based on modes at $\sim 500 \mathrm{~cm}^{-1}$ are not the same as observed for the neutral isomer, showing the effect of the proton on the cycle (contrary to the spectra of molecules protonated on the amino group, which look like that of the neutrals). ${ }^{29}$ Previous calculations on protonated benzene ${ }^{33}$ or phenol ${ }^{34}$ have predicted that proton localization on a carbon of the aromatic skeleton should lead to broad quasi structure-less spectra due to a barrier-less internal conversion process, which seems to be similar to what is observed for $m$-aminophenolH ${ }^{+}$.

The $a b$ initio calculations necessary for a more complete assignment are problematic since there is a discrepancy between the MP2 and DFT calculations for the ground state of $m$-aminophenolH ${ }^{+}$. With MP2 calculations, both the $\mathrm{NH}_{3}{ }^{+}$ and the $\mathrm{C} \mathrm{H}^{+}$tautomers have very similar ground state energies and then should both be present in the ion trap. In contrast, the DFT calculations predict that $\mathrm{C} \mathrm{H}^{+}$is more stable by $0.3 \mathrm{eV}$ (cis isomer) or $0.4 \mathrm{eV}$ (trans isomer) as compared to the $\mathrm{NH}_{3}{ }^{+}$ tautomer. The oscillator strengths have been calculated for the $\mathrm{S}_{1} \leftarrow \mathrm{S}_{0}$ transitions of $\mathrm{C}_{6} \mathrm{H}^{+}$and $\mathrm{NH}_{3}{ }^{+}$tautomers and they are within a factor of 2 . Excited state optimization indicates a large geometry change between the ground and excited states of the $\mathrm{C} 6 \mathrm{H}^{+}$tautomer, so that the FC factors should be smaller as compared to those of the $\mathrm{NH}_{3}{ }^{+}$tautomer. Thus the excitation efficiency of the $\mathrm{NH}_{3}{ }^{+}$tautomer should be greater than that of $\mathrm{C} \mathrm{H}^{+}$. However the $\mathrm{NH}_{3}{ }^{+}$tautomer is not observed, thus one can deduce that it is not present (or in a very small amount) in the cold ion trap, and consequently less stable than the $\mathrm{C}_{6} \mathrm{H}^{+}$tautomer.

This implies also that, for ground state calculations, DFT is more reliable than MP2, which seems to fail rather badly in the present case. In contrast, the TD-DFT method does not give correct results for excited state calculations since the presence of a calculated charge transfer $\left(\pi \sigma^{*}\right)$ state forbids the excited state optimization in the case of the $\mathrm{NH}_{3}{ }^{+}$tautomers. As shown also previously, the $\mathrm{CC} 2$ or $\mathrm{ADC}(2)$ methods are quite good for excited state calculations ${ }^{21,35,36}$ and in the present case, the $\operatorname{ADC}(2)$ method gives adiabatic energies in quite good agreement with the experimental values for ortho and paraaminophenolH ${ }^{+}\left(\mathrm{NH}_{3}{ }^{+}\right.$tautomers). For $m$-aminophenolH ${ }^{+}$, the $\mathrm{C} \mathrm{H}^{+}$adiabatic energies are calculated at $3.59 \mathrm{eV}$ and $3.54 \mathrm{eV}$ (cis and trans). The $\mathrm{C} 4 \mathrm{H}^{+}$tautomer, which may be populated in the trap since its ground state energy is only $0.1 \mathrm{eV}$ higher than that of $\mathrm{C} \mathrm{H}^{+}$, has a calculated vertical transition energy of around $0.5 \mathrm{eV}$ lower than that of the $\mathrm{C} 6 \mathrm{H}^{+}$tautomer. The adiabatic transition energy for the cis meta $\mathrm{C}_{4} \mathrm{H}^{+}$tautomer is calculated at $3.34 \mathrm{eV}$, not far from the origin of the first band 
system, while for the trans meta $\mathrm{C} 4 \mathrm{H}^{+}$tautomer there seems to be a conical intersection between the excited and the ground state.

To sum up, a reasonable assignment for the $m$-aminophenolH ${ }^{+}$ photofragmentation spectrum would be to assign the band system starting at $3.39 \mathrm{eV}$ to the $\mathrm{S}_{1} \leftarrow \mathrm{S}_{0}$ transition of the $\mathrm{C}_{4} \mathrm{H}^{+}$tautomer, and the second band system starting at $3.85 \mathrm{eV}$ to the $\mathrm{S}_{1} \leftarrow \mathrm{S}_{0}$ transition of the $\mathrm{C} \mathrm{H}^{+}$tautomer. The third band system starting at $4.85 \mathrm{eV}$ may be assigned to the $\mathrm{S}_{2} \leftarrow \mathrm{S}_{0}$ transition of the $\mathrm{C} 6 \mathrm{H}^{+}$ tautomer calculated at $5.6 \mathrm{eV}$ vertically.

\section{Determination of the most stable protonation site}

For protonated species there are not so many experiments which are able to determine the most abundant tautomer under well-defined conditions. Usually the temperature of the ions is not known nor measured and the observation method is not necessarily unambiguous. Besides, it has been shown that the proton is not necessarily localized on one structure at a high temperature. ${ }^{16}$ Determination of the protonation site by collision processes relies on the assumption that the tautomerization rate is slower than other reaction/fragmentation processes and this assumption is not so obvious owing to a small barrier to the tautomerisation process, around $1 \mathrm{eV}$ in an aromatic ring. ${ }^{15}$

Detection of tautomers through IR spectroscopy is another approach, often realized through IRMPD on hot ions and the spectroscopy is not unambiguous due to the highly nonlinear multiphoton absorption process leading to the absence of some vibrational bands.

The approach of electronic photo-fragmentation of cold ions can be a powerful alternative but one has to be aware that some assumptions are also behind the measurement. In particular, quantitative relationship between the ion intensity and the stability of the tautomer/conformer may not be so easy to get.

The fragmentation process might depend on the tautomer. However the excitation energy is such $(4 \mathrm{eV})$ that, when the excited state undergoes internal conversion, the randomization between tautomers (barrier around $1 \mathrm{eV})^{15}$ is realized, thus the fragmentation rate should be the same for all tautomers.

The excitation efficiency, which depends on the oscillator strength of the electronic transition and on the Franck-Condon (FC) factors, is more difficult to evaluate. The oscillator strength can be calculated and in the present case it has the same order of magnitude for the $\mathrm{C}_{6} \mathrm{H}^{+}$and $\mathrm{NH}_{3}{ }^{+}$tautomers of $m$-aminophenolH ${ }^{+}$(within a factor 2 ). When the ground and excited state optimized geometries are similar, the FC factors can be calculated using calculated ground and excited vibrational frequencies. When there is a large change in the optimized geometry between ground and excited states, the density of states in the Franck-Condon window is such that Franck Condon analysis becomes impossible and the Franck-Condon factors are very weak. In the case of the $m$-aminophenolH ${ }^{+}$isomers, the distortion in geometry of the $\mathrm{C} \mathrm{H}^{+}$tautomer (this holds also for $\mathrm{C}_{4} \mathrm{H}^{+}$) in $\mathrm{S}_{1}$ is larger than for the $\mathrm{NH}_{3}{ }^{+}$tautomer, which can be easily deduced from the difference between vertical and the adiabatic transition energies: a change of less than $0.5 \mathrm{eV}$ for the $\mathrm{NH}_{3}{ }^{+}$tautomer, as in anilinium or in $p$-aminophenolH ${ }^{+}$, indicates a relatively small geometry change associated with a strong 0-0 transition and a well resolved spectrum. On the other hand, a difference of $1 \mathrm{eV}$ or more between vertical and adiabatic energies indicates a large geometry change that leads to weak Franck-Condon factors. These considerations imply that if the $\mathrm{NH}_{3}{ }^{+}$tautomer was present, it would have been observed quite easily as in the case of ortho and para-aminophenolH ${ }^{+}$. Thus we can conclude that the $\mathrm{C}_{6} \mathrm{H}^{+}$and $\mathrm{C} 4 \mathrm{H}^{+}$are by far the most abundant conformers in the experiment and, if thermal equilibrium at $50 \mathrm{~K}$ is assumed, these tautomers should be the most stable ones. The absence of the $\mathrm{NH}_{3}{ }^{+}$tautomer is not compatible with MP2 calculations, which predict that $\mathrm{NH}_{3}{ }^{+}$and $\mathrm{C}_{6} \mathrm{H}^{+}$tautomers have the same ground state energy, but it matches with DFT calculations.

We are very surprised by the inconsistency between the two methods, which usually gives similar results, but in this case are in strong disagreement as far as the $\mathrm{NH}_{3}{ }^{+}$tautomer is concerned, while for the $\mathrm{C} 2 \mathrm{H}^{+}, \mathrm{C} 4 \mathrm{H}^{+}, \mathrm{C} 5 \mathrm{H}^{+}$tautomers both methods give very similar results. These results show that there is a problem in the calculation methods but it is beyond our competence and is certainly a problem that theoreticians have to solve. $\S$

The stronger proton affinity of the meta-isomer for the C6 and $\mathrm{C} 4$ carbon atoms can be explained by a resonance effect. It is known that electron donating groups with lone pairs $\left(\mathrm{OH},-\mathrm{NH}_{2}\right)$ on the atoms adjacent to the $\pi$ system activate the aromatic ring by increasing the electron density on the ring through a resonance donating effect that allows electron density to be positioned at the ortho- and para- positions. For para- and ortho-aminophenol $\mathrm{H}^{+}$isomers, the resonance effect due to $\mathrm{OH}$ and $\mathrm{NH}_{2}$ groups acts on different carbon atoms, whereas in meta-aminophenolH ${ }^{+}$both substituents induce electron density on the same carbon atoms increasing their negative charge thus their proton affinity, which becomes larger than that of the amino group and indeed, both $\mathrm{C} 4 \mathrm{H}^{+}$ and $\mathrm{C}_{6} \mathrm{H}^{+}$tautomers seem to be observed.

\section{Electrospray source and produced ions}

There is an active discussion on the relationship between the most stable ions in solution and the ions obtained in the gas phase after the electrospray process. ${ }^{22,23}$ We have calculated the stability of the $\mathrm{NH}_{3}{ }^{+}$and the $\mathrm{C} \mathrm{H}^{+}$tautomers of metaaminophenolH ${ }^{+}$in solution using the COSMO model implemented in Turbomole at the DFT/B3LYP level. Interestingly, there is a complete reversal of the stability between the gas and solution phase for these two tautomers. As seen in the ESI $\dagger$ (Fig. S3), the absorption spectrum of the meta-aminophenol in solution $\left(\mathrm{H}_{2} \mathrm{O}-\right.$ methanol) at two different pHs shows a blue shift of the absorption at low $\mathrm{pH}$ (at $270 \mathrm{~nm}$ ) only compatible with protonation on the amino group. The $\mathrm{NH}_{3}{ }^{+}$form is calculated to be $0.3 \mathrm{eV}$ more stable than the $\mathrm{C} \mathrm{H}^{+}$form in solution and this structure is less stable by $0.3 \mathrm{eV}$ in the gas phase. The absence of the $\mathrm{NH}_{3}{ }^{+}$conformer in the ion trap clearly shows that the liquid equilibrium is not conserved in the electrospray process, at least in our experimental setup.

$\S$ Similar calculations have been done with another software and similar results were obtained. 


\section{E. Conclusions}

In this paper it is shown that one can use electronic spectroscopy to identify the most abundant protonated tautomers at a low temperature, which are probably the most stable. In particular it shows that in the para- and ortho- isomers of protonated aminophenol, the proton is attached to the amino group while it is linked to a carbon atom of the aromatic ring in the meta- isomer. This experiment also shows that the most stable tautomers cannot be always predicted by $a b$ initio calculations as long as the large discrepancies between MP2 and DFT methods are not understood. It seems also that the most stable tautomeric structure is not conserved upon transfer from the liquid phase to the gas phase.

\section{Acknowledgements}

This work was supported by the ANR Research Grant (ANR2010BLANC040501). We acknowledge the use of the computing facility cluster GMPCS of the LUMAT federation (FR LUMAT 2764). We thank Dr Anne Zehnacker and Prof. Ernesto Marceca for fruitful discussions.

\section{Notes and references}

1 Carbonium ions: Volume I, ed. G. A. Olah and P. V. R. Schleyer, Interscience, New York, 1968.

2 Carbocation Chemistry, ed. G. A. Olah and G. K. S. Prakash, Wiley-Interscience, John Wiley, 2004.

3 G. a. Olah, A. M. White and D. H. O'Brien, Chem. Rev., 1970, 70, 561.

4 N. Solca and O. Dopfer, J. Chem. Phys., 2004, 120, 10470-10482.

5 F. M. Pasker, N. Solcà and O. Dopfer, J. Phys. Chem. A, 2006, 110, 12793-12804.

6 U. J. Lorenz, N. Solcà, J. Lemaire, P. Maître and O. Dopfer, Angew. Chem., Int. Ed., 2007, 46, 6714-6716.

7 O. Dopfer, N. Solcà, J. Lemaire, P. Maitre, M.-E. Crestoni and S. Fornarini, J. Phys. Chem. A, 2005, 109, 7881-7887.

8 D. Zhao, J. Langer, J. Oomens and O. Dopfer, J. Chem. Phys., 2009, 131, 184307.

9 G. E. Douberly, A. M. Ricks, P. v. R. Schleyer and M. A. Duncan, J. Phys. Chem. A, 2008, 112, 4869-4874.

10 B. Bandyopadhyay, T. C. Cheng, S. E. Wheeler and M. A. Duncan, J. Phys. Chem. A, 2012, 116, 7065-7073.

11 M. Z. Kamrath, E. Garand, P. a. Jordan, C. M. Leavitt, A. B. Wolk, M. J. Van Stipdonk, S. J. Miller and M. a, Johnson, J. Am. Chem. Soc., 2011, 133, 6440-6448.

12 A. M. Ricks, G. E. Douberly and M. a. Duncan, Astrophys. J., 2009, 702, 301-306.

13 J.-Y. Salpin, S. Guillaumont, J. Tortajada, L. MacAleese, J. Lemaire and P. Maitre, ChemPhysChem, 2007, 8, 2235-2244.

14 D. Scuderi, V. Lepere, G. Piani, A. Bouchet and A. ZehnackerRentien, J. Phys. Chem. Lett., 2014, 5, 56-61.
15 A. Škríba, Š. Janková, J. Váňa, P. Barták, P. Bednář, P. Fryčák, L. Kučera, O. Kurka, K. Lemr, P. Macíková, E. Marková, P. Nováková, B. Papoušková, J. Skopalová, H. Švecová and J. Roithová, Int. J. Mass Spectrom., 2013, 337, 18-23.

16 G. Grégoire, M. P. Gaigeot, D. C. Marinica, J. Lemaire, J. P. Schermann and C. Desfrançois, Phys. Chem. Chem. Phys., 2007, 9, 3082-3097.

17 T. R. Rizzo, J. A. Stearns and O. Boyarkin, Int. Rev. Phys. Chem., 2009, 28, 481-515.

18 N. S. Nagornova, T. R. Rizzo and O. V. Boyarkin, J. Am. Chem. Soc., 2010, 132, 4040-4041.

19 I. Alata, J. Bert, M. Broquier, C. Dedonder, G. Feraud, G. Grégoire, S. Soorkia, E. Marceca and C. Jouvet, J. Phys. Chem. A, 2013, 117, 4420-4427.

20 G. Féraud, M. Broquier, C. Dedonder-Lardeux, G. Grégoire, S. Soorkia and C. Jouvet, Phys. Chem. Chem. Phys., 2014, 16, 5250-5259.

21 M. Berdakin, G. Féraud, C. Dedonder-Lardeux, C. Jouvet and G. A. Pino, Phys. Chem. Chem. Phys., 2014, 16, 10643-10650.

22 J. R. Joyce and D. S. Richards, J. Am. Soc. Mass Spectrom., 2011, 22, 360-368.

23 Z. Tian and S. R. Kass, Angew. Chem., Int. Ed., 2009, 48, 1321-1323.

24 R. Ahlrichs, M. Bär, M. Häser, H. Horn and C. Kölmel, Chem. Phys. Lett., 1989, 162, 165.

25 C. Hättig and F. Weigend, J. Chem. Phys., 2000, 113, 5154.

26 B. Trofimov, G. Stelter and J. Schirmer, J. Chem. Phys., 2002, 117, 6402.

27 A. Klamt and G. Schüürmann, J. Chem. Soc., Perkin Trans. 2, 1993, 799.

28 A. L. Sobolewski, W. Domcke, C. Dedonder-Lardeux and C. Jouvet, Phys. Chem. Chem. Phys., 2002, 4, 1093-1100.

29 G. Féraud, M. Broquier, C. Dedonder-Lardeux, G. Grégoire, S. Soorkia and C. Jouvet, Phys. Chem. Chem. Phys., 2014, 16, 5250 .

30 S. Wategaonkar and S. Doraiswamy, J. Chem. Phys., 1996, $105,1786$.

31 M. C. Capello, M. Broquier, S. I. Ishiuchi, W. Y. Sohn, M. Fujii, C. Dedonder-Lardeux, C. Jouvet and G. a. Pino, J. Phys. Chem. A, 2014, 118, 2056-2062.

32 K. Remmers, W. L. Meerts, A. Zehnacker-Rentien, K. Le Barbu and F. Lahmani, J. Chem. Phys., 2000, 112, 6237.

33 M. Rode, A. L. Sobolewski, C. Dedonder, C. Jouvet and O. Dopfer, J. Phys. Chem. A, 2009, 113, 5865-5873.

34 S. Azizkarimi, R. Omidyan and G. Azimi, Chem. Phys. Lett., 2013, 555, 19-25.

35 M. Schreiber, M. R. Silva-Junior, S. P. a. Sauer and W. Thiel, J. Chem. Phys., 2008, 128, 134110.

36 R. Send, M. Kühn and F. Furche, J. Chem. Theory Comput., 2011, 7, 2376-2386. 